TITLE:

\title{
Electrochemical QCM Study of the Synthesis Process of Cobalt Nanoparticles via Electroless Deposition
}

\section{$\operatorname{AUTHOR}(\mathrm{S}):$}

Yagi, Shunsuke; Kawamori, Makoto; Matsubara, Eiichiro

\section{CITATION:}

Yagi, Shunsuke ... [et al]. Electrochemical QCM Study of the Synthesis Process of Cobalt Nanoparticles via Electroless Deposition. ELECTROCHEMICAL AND SOLID STATE LETTERS 2010, 13(2): E1-E3

ISSUE DATE:

2010

URL:

http://hdl.handle.net/2433/109934

RIGHT:

(C) 2010 The Electrochemical Society 


\title{
Electrochemical QCM Study of the Synthesis Process of Cobalt Nanoparticles via Electroless Deposition
}

\author{
Shunsuke Yagi, ${ }^{*, z}$ Makoto Kawamori, and Eiichiro Matsubara \\ Department of Materials Science and Engineering, Kyoto University, Kyoto 606-8501, Japan
}

The synthesis process of cobalt nanoparticles via electroless deposition in ethylene glycol (EG) was investigated by electrochemical quartz crystal microbalance (QCM). The oxidation-reduction potential of the Co(II)/Co redox pair in EG could not be thermodynamically calculated because of insufficient thermodynamic data in organic solvents. We experimentally determined the oxidation-reduction potential of the $\mathrm{Co}(\mathrm{II}) / \mathrm{Co}$ redox pair in EG by cyclic voltammetry combined with QCM. The reaction start and end points were also determined by QCM. The effect of the nucleating agent $\mathrm{H}_{2} \mathrm{PtCl}_{6} \cdot 6 \mathrm{H}_{2} \mathrm{O}$ on the cobalt deposition behavior and particle size distribution was examined.

(c) 2009 The Electrochemical Society. [DOI: 10.1149/1.3269051] All rights reserved.

Manuscript submitted September 14, 2009; revised manuscript received November 2, 2009. Published December 7, 2009.

The ferromagnetic nanoparticles of iron group metals (i.e., iron, cobalt, and nickel) have been widely investigated due to their unique properties different from bulk ${ }^{1}$ and their high potential in applications such as catalysts, magnetic fluids, and magnetic recording media. Ferromagnetic nanoparticles can also be aligned to achieve twoor three-dimensional structuration by external magnetic fields. ${ }^{2}$ Liquid-phase synthesis of ferromagnetic nanoparticles, including thermal decomposition, ${ }^{3,4}$ electroless deposition using a reducing agent, ${ }^{5,6}$ and polyol reduction, ${ }^{7,8}$ is one of the simplest methods among numerous synthesis processes reported and is suitable for volume production at low cost.

We reported liquid-phase synthesis processes of copper, ${ }^{9,10}$ nickel, ${ }^{11}$ cobalt, ${ }^{12}$ and tin $^{13}$ nanoparticles by electroless deposition. We also proposed the thermodynamical oxidation-state control of nanoparticles by comparing the mixed potential measured in the reaction solution with Pourbaix diagrams. ${ }^{10,14}$ However, thermodynamic calculation cannot be easily adopted to reaction systems using organic solvents because of the lack of thermodynamic data in organic solvents. Furthermore, a kinetic investigation is not sufficient for the electroless synthesis process of nanoparticles specifically in the presence of nucleating agents such as silver nitrate $\left(\mathrm{AgNO}_{3}\right)$, palladium chloride $\left(\mathrm{PdCl}_{2}\right)$, and hexachloroplatinic acid hexahydrate $\left(\mathrm{H}_{2} \mathrm{PtCl}_{6} \cdot 6 \mathrm{H}_{2} \mathrm{O}\right)$.

In the present work, the effect of the nucleating agent $\mathrm{H}_{2} \mathrm{PtCl}_{6} \cdot 6 \mathrm{H}_{2} \mathrm{O}$ on the deposition behavior of cobalt nanoparticles and its particle size distribution is investigated by quartz crystal microbalance $(\mathrm{QCM})^{15}$ in conjunction with the mixed potential measurement. Moreover, the oxidation-reduction potential of the $\mathrm{Co}(\mathrm{II}) / \mathrm{Co}$ redox pair in ethylene glycol (EG) is determined by electrochemical QCM.

\section{Experimental}

Synthesis method and characterization of cobalt nanoparticles.-Reaction solutions were prepared using reagent-grade cobalt chloride hexahydrate $\left(\mathrm{CoCl}_{2} \cdot 6 \mathrm{H}_{2} \mathrm{O}\right)$, EG, sodium hydroxide $(\mathrm{NaOH})$, hydrazine monohydrate $\left(\mathrm{N}_{2} \mathrm{H}_{4} \cdot \mathrm{H}_{2} \mathrm{O}\right)$, and hexachloroplatinic acid hexahydrate $\left(\mathrm{H}_{2} \mathrm{PtCl}_{6} \cdot 6 \mathrm{H}_{2} \mathrm{O}\right)$ (Nacalai Tesque, Inc.) as received. First, $27 \mathrm{~cm}^{3}$ of EG solution containing $0.10 \mathrm{M} \mathrm{CoCl}_{2}$, $1.4 \mathrm{M} \mathrm{NaOH}$, and $\mathrm{H}_{2} \mathrm{PtCl}_{6}(0-20 \mathrm{mM})$ was prepared. The $\mathrm{Co}$ (II) ions in this solution were hydroxylated to form a green Co(II) hydroxide sol. Meanwhile, $27 \mathrm{~cm}^{3}$ of EG solution containing $1.0 \mathrm{M}$ $\mathrm{N}_{2} \mathrm{H}_{4}$ and $0.6 \mathrm{M} \mathrm{NaOH}$ was prepared. The temperature of the solutions was kept at a reaction temperature of $353 \mathrm{~K}$ on a hot plate with nitrogen gas bubbling $\left(50 \mathrm{~cm}^{3} \mathrm{~min}^{-1}\right)$ starting $30 \mathrm{~min}$ before the reaction and lasting throughout the reaction to eliminate the effect of dissolved oxygen. These solutions were mixed at $353 \mathrm{~K}$ to start the

\footnotetext{
* Electrochemical Society Active Member.

${ }^{\text {z }}$ E-mail: syagi@mtl.kyoto-u.ac.jp
}

reaction and were agitated at a rate of $500 \mathrm{rpm}$ with a magnetic stirring unit. The total amount of the reaction solution was $54 \mathrm{~cm}^{3}$, and thus the reaction EG suspension contained $0.050 \mathrm{M} \mathrm{CoCl}_{2}, 0.50$ $\mathrm{M} \mathrm{N}_{2} \mathrm{H}_{4}$, and $1.0 \mathrm{M} \mathrm{NaOH}$.

The morphology of cobalt nanoparticles was observed using a field-emission-scanning electron microscope (JEOL Ltd., JSM$6500 \mathrm{~F})$. The mean diameter and size distribution of the cobalt particles were determined by image analysis for 300 particles in each sample.

In situ measurement of cobalt deposition by QCM.- Cobalt deposition was investigated in situ by QCM using a round $9 \mathrm{MHz}$ AT-cut quartz crystal substrates, on both sides of which gold layers with a diameter of $5.0 \mathrm{~mm}$ were sputtered with an underlying titanium buffer layer. The gold-sputtered QCM substrate was fixed inside a dipping-type Teflon holder (Seiko EG\&G QCA917-21). The electrochemically active area of the QCM substrate was $0.196 \mathrm{~cm}^{2}$. The holder with an oscillating circuit was connected to a frequency counter (Seiko EG\&G QCA917) with a coaxial cable. The weight of cobalt deposited on the QCM substrate, $\Delta m$, was calculated from the change in resonance frequency of the QCM substrate, $\Delta f(<0)$, by the Sauerbrey equation

$$
-\Delta f=\frac{2 f_{0}^{2} \Delta m}{A \sqrt{\rho_{\mathrm{q}} \mu_{\mathrm{q}}}}
$$

where $f_{0}$ is the frequency of the QCM substrate before the deposition, $A$ is the active area of the QCM substrate $\left(0.196 \mathrm{~cm}^{2}\right), \rho_{\mathrm{q}}$ is the density of quartz $\left(2.648 \mathrm{~g} \mathrm{~cm}^{-3}\right)$, and $\mu_{\mathrm{q}}$ is the shear modulus of quartz $\left(2.947 \times 10^{11} \mathrm{~g} \mathrm{~cm}^{-1} \mathrm{~s}^{-2}\right)$. The immersion potential of the QCM substrate was measured during several experimental runs by a potentiostat/galvanostat (Hokuto Denko Co., Ltd., HA-151), and it was assumed that the measured immersion potential was almost the same as the mixed potential in the reaction suspension in this system. The cyclic voltammogram was also measured using the potentiostat/galvanostat. $\mathrm{A} \mathrm{Ag} / \mathrm{AgCl}$ electrode (Horiba 2565A-10T) and a platinum electrode $(20 \times 20 \mathrm{~mm})$ were used as reference and counter electrodes, respectively.

\section{Results and Discussion}

Figure 1 shows scanning electron microscopy (SEM) images and particle size distributions of cobalt spherical nanoparticles synthesized at various amounts of the nucleating agent $\mathrm{H}_{2} \mathrm{PtCl}_{6}$. In the absence of the nucleating agent, the largest particles, $926 \mathrm{~nm}$ in mean diameter, were obtained. The mean diameter apparently decreased with increasing amount of the nucleating agent, and the smallest particles, $98 \mathrm{~nm}$ in mean diameter, were obtained at the maximum concentration examined $\left(\left[\mathrm{H}_{2} \mathrm{PtCl}_{6}\right]=10.0 \mathrm{mM}\right)$. As indicated in Fig. 1a, the size distribution of cobalt particles was polydispersed and broadened without the addition of the nucleating agent. With increasing amount of nucleating agent, the histogram of the size distribution became sharper, suggesting that the addition of 

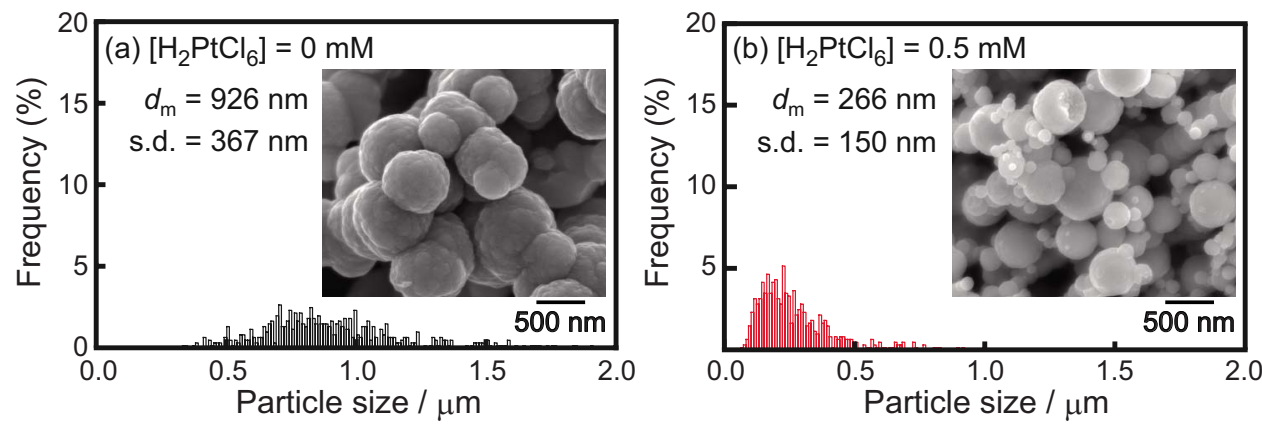

Figure 1. (Color online) SEM images and size distributions of cobalt particles synthesized using solutions containing (a) 0 ,
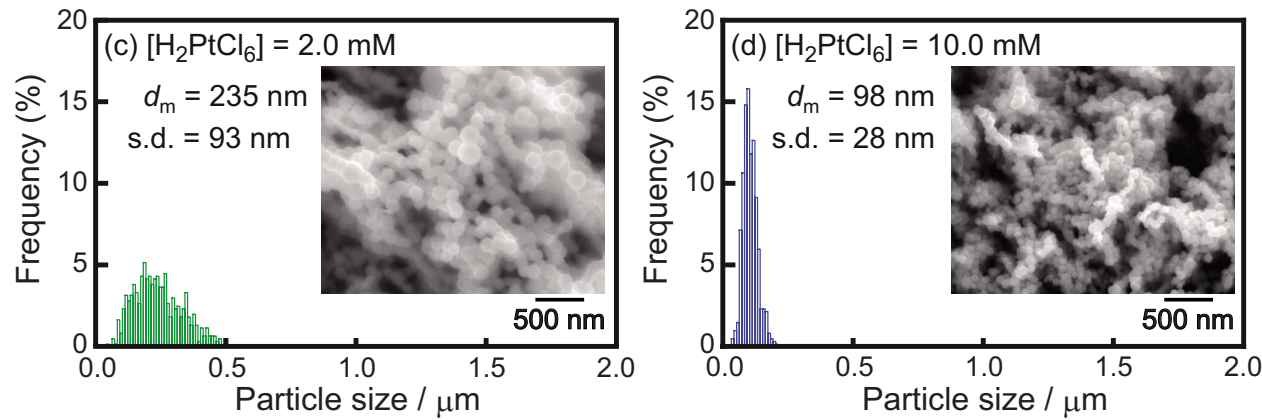
(b) 0.5 , (c) 2.0 , and (d) $10.0 \mathrm{mM} \mathrm{H}_{2} \mathrm{PtCl}_{6}$ nucleating agents. Mean diameter $\left(d_{\mathrm{m}}\right)$ and standard deviation (s.d.) are also indicated.

the nucleating agent $\mathrm{H}_{2} \mathrm{PtCl}_{6}$ separates the nucleaction and growth stages in the formation process of cobalt nanoparticles. ${ }^{16} \mathrm{X}$-ray diffraction revealed that all particles obtained were mixtures of facecentered cubic and hexagonal close-packed cobalt particles regardless of the absence or presence of the nucleating agents (data are not shown).

For further discussion, partial oxidation-reduction reactions are separately considered. In the present process, minute platinum nuclei are first formed by the reduction of $\mathrm{Pt}(\mathrm{IV})$ species, and the following two reactions subsequently occur as cathodic partial reactions because the oxidation-reduction potential of $\mathrm{Pt}(\mathrm{IV}) / \mathrm{Pt}$ redox pair is much higher than those of the $\mathrm{Co}(\mathrm{II}) / \mathrm{Co}$ and $\mathrm{H}_{2} \mathrm{O} / \mathrm{H}_{2}$ redox pairs

Cobalt deposition

$$
\mathrm{Co}(\mathrm{II})+2 \mathrm{e} \rightarrow \mathrm{Co}
$$

Hydrogen generation

$$
2 \mathrm{H}_{2} \mathrm{O}+2 \mathrm{e} \rightarrow \mathrm{H}_{2}+2 \mathrm{OH}^{-}
$$

where $\mathrm{Co}(\mathrm{II})$ represents all the cobalt(II) species, e.g., $\mathrm{Co}^{2+}$, $\mathrm{Co}(\mathrm{OH})_{2}, \mathrm{HCoO}_{2}^{-}$or $\mathrm{Co}(\mathrm{OH})_{3}^{-}$, and $\mathrm{CoO}_{2}^{2}-$ or $\mathrm{Co}(\mathrm{OH})_{4}^{2-}{ }^{-17}$ Water comes from hydrates such as cobalt chloride hexahydrate, hydrazine monohydrate, and chloroplatinic acid hexahydrate added as metallic salt, reducing agent, and nucleating agent, respectively. Water is also generated by the aggregation of $\mathrm{H}^{+}$ions dissociated from hydroxyl groups of $\mathrm{EG}$ and $\mathrm{OH}^{-}$ions from $\mathrm{NaOH}$.

However, the following hydrazine oxidation reactions mainly occur as anodic partial reactions

$$
\begin{gathered}
\mathrm{N}_{2} \mathrm{H}_{4}+4 \mathrm{OH}^{-} \rightarrow \mathrm{N}_{2}+4 \mathrm{H}_{2} \mathrm{O}+4 \mathrm{e} \\
\mathrm{N}_{2} \mathrm{H}_{4}+\mathrm{OH}^{-} \rightarrow \frac{1}{2} \mathrm{~N}_{2}+\mathrm{NH}_{3}+\mathrm{H}_{2} \mathrm{O}+\mathrm{e}
\end{gathered}
$$

Figure 2 depicts cyclic voltammograms measured at $1 \mathrm{mV} \mathrm{s}^{-1}$ in $120 \mathrm{~cm}^{3}$ of EG containing $0.050 \mathrm{M} \mathrm{CoCl}_{2} \cdot 6 \mathrm{H}_{2} \mathrm{O}$ and $1.0 \mathrm{M}$ $\mathrm{NaOH}$ by a potentiostat using the gold-sputtered QCM substrate as a working electrode. The usual cyclic voltammogram by a potentiostat includes all the information of oxidation-reduction reactions on the QCM substrate. However, the cyclic voltammogram drawn using the weight change of the QCM substrate only contains the information of cobalt deposition and cobalt dissolution. In the cyclic voltammogram by QCM, the cathodic current of cobalt deposition is seen below ca. $-0.98 \mathrm{~V}$ vs $\mathrm{Ag} / \mathrm{AgCl}$ during the cathodic sweep. Once cobalt completely covers the gold-sputtered QCM substrate, cobalt is deposited below ca. $-0.85 \mathrm{~V}$. Therefore, cobalt has a higher catalytic activity for cobalt deposition than gold, resulting in the small overpotential. Above $-0.85 \mathrm{~V}$, the anodic current of cobalt dissolution is observed up to $-0.64 \mathrm{~V}$. Thus, the oxidation-reduction potential of the $\mathrm{Co}(\mathrm{II}) / \mathrm{Co}$ redox pair can be determined to be approximately $-0.85 \mathrm{~V}$ vs $\mathrm{Ag} / \mathrm{AgCl}$. In the usual cyclic voltammogram by a potentiostat, the cathodic current of hydrogen generation (reductive decomposition of water or EG) is observed below $-1.04 \mathrm{~V}$ in addition to the cathodic current of cobalt deposition. The oxidization current of adsorbed hydrogen on the QCM substrate is observed above $-1.04 \mathrm{~V}$ only in the anodic sweep.

Figure 3 shows the weight of cobalt deposited on the QCM substrate during the nanoparticle synthesis. The deposition rate and the total amount of cobalt deposited on the QCM substrate at certain times decreased with the increase in the nucleating agent. This is

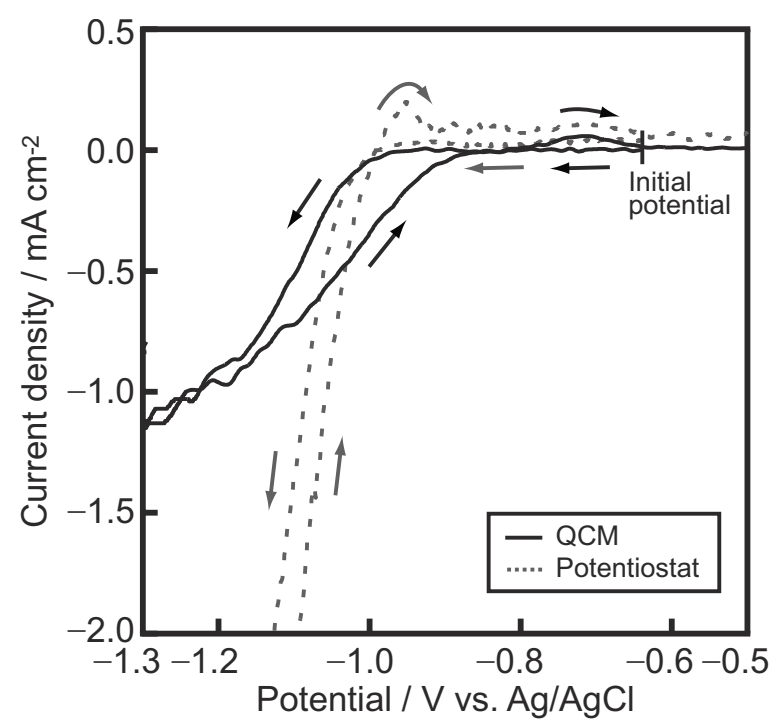

Figure 2. Cyclic voltammograms measured at $1 \mathrm{mV} \mathrm{s}^{-1}$ in $\mathrm{EG}$ containing $\left[\mathrm{CoCl}_{2} \cdot 6 \mathrm{H}_{2} \mathrm{O}\right]=0.050 \mathrm{M}$ and $[\mathrm{NaOH}]=1.0 \mathrm{M}$ by a potentiostat (dotted line) and QCM (solid line). The initial potential is $-0.64 \mathrm{~V}$. 


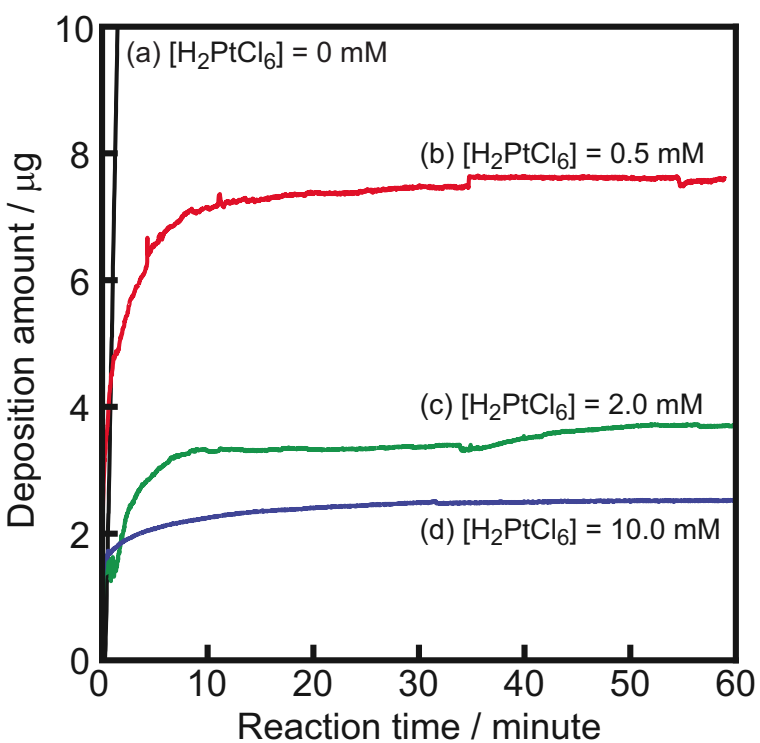

Figure 3. (Color online) Weight of cobalt deposited on a gold-sputtered QCM substrate from solutions containing (a) 0, (b) 0.5, (c) 2.0, and (d) 10.0 $\mathrm{mM} \mathrm{H} \mathrm{HtCl}_{6}$ nucleating agents.

because the nucleating agent provides numerous nucleation sites in the reaction solution, which lowers the number of cobalt atoms deposited as one particle as well as the amount of cobalt deposited on the QCM substrate. Thus, the addition of a large amount of the nucleating agent results in the formation of minute cobalt nanoparticles. According to the result of QCM, the curve is almost constant after $30 \mathrm{~min}$, indicating that the reaction end point is around $30 \mathrm{~min}$.

Figure 4 shows the change in the mixed potential measured in the reaction suspension. The initial mixed potential is in the range of -1.08 to $-0.98 \mathrm{~V}$ vs $\mathrm{Ag} / \mathrm{AgCl}$, and the mixed potential gradually increases with time. However, the mixed potential is always below the oxidation-reduction potential of the $\mathrm{Co}$ (II)/Co redox pair $(-0.85$ $\mathrm{V})$, indicating that cobalt nanoparticles can be deposited in this re-

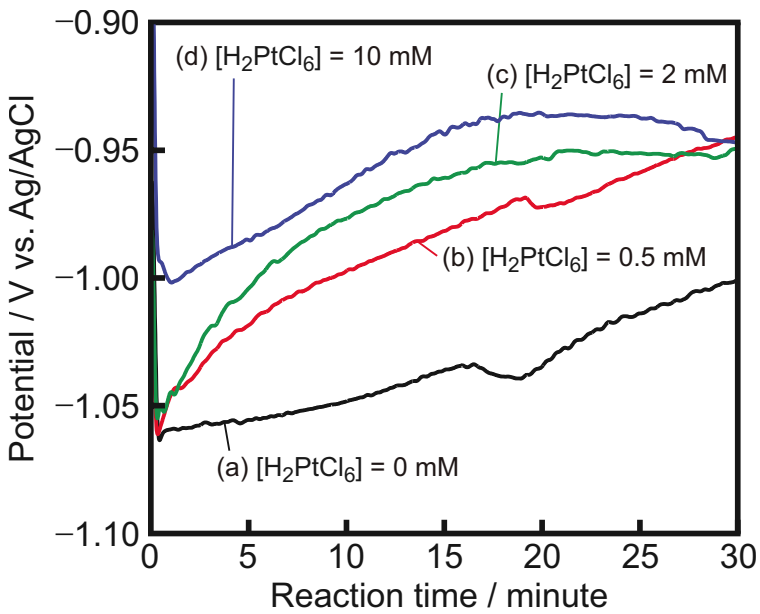

Figure 4. (Color online) Change in mixed potential measured using a goldsputtered QCM substrate in solutions containing (a) 0, (b) 0.5 , (c) 2.0, and (d) $10.0 \mathrm{mM} \mathrm{H}_{2} \mathrm{PtCl}_{6}$ nucleating agents. action system in at least $30 \mathrm{~min}$. The mixed potential also increases with the additive amount of the nucleating agent. This is because minute cobalt particles are formed with the increasing amount of the nucleating agent, which provides numerous active catalytic sites for hydrazine oxidation, resulting in the extensive consumption of hydrazine. The amount of hydrazine consumed for the reduction of cobalt(II) species is the same when all the cobalt(II) species are reduced and, therefore, the difference in mixed potential is predominantly due to the difference in the amount of hydrazine consumed for hydrogen generation.

\section{Conclusion}

The synthesis process of cobalt nanoparticles via electroless deposition in EG was investigated by QCM. Through the present work, we obtained the following results.

The oxidation-reduction potential of the $\mathrm{Co}(\mathrm{II}) / \mathrm{Co}$ redox pair in EG at $353 \mathrm{~K}$ in this reaction system was estimated to be about $-0.85 \mathrm{~V}$ vs $\mathrm{Ag} / \mathrm{AgCl}$ by cyclic voltammetry in combination with QCM. The nucleating agent $\mathrm{H}_{2} \mathrm{PtCl}_{6} \cdot 6 \mathrm{H}_{2} \mathrm{O}$ provides nucleation sites for cobalt deposition, resulting in the formation of small cobalt particles. The nucleating agent also sharpens the particle size distribution; this implies that the formation of platinum nuclei divides the nucleation and growth stages in the formation of cobalt nanoparticles. The reaction start and end points can be determined in situ by QCM; the cobalt deposition reaction starts immediately after the mixing of the hydrazine and metallic salt solutions and finishes after around $30 \mathrm{~min}$.

\section{Acknowledgments}

This research was supported by a grant-in-aid for Knowledge Cluster Initiative (Kyoto Nanotechnology Cluster), Grant-in-Aid for the Global COE Program (International Center for Integrated Research and Advanced Education in Materials Science), and Grantin-Aid for Young Scientists (B 20760505), all from the Japan Society for the Promotion of Science, Ministry of Education, Culture, Sports, Science and Technology of Japan. This research was also supported by the Kurata Memorial Hitachi Science and Technology Foundation and the Shorai Foundation for Science and Technology.

Kyoto University assisted in meeting the publication costs of this article

\section{References}

O. Kitakami, H. Sato, and Y Shimada, Phys. Rev. B, 56, 13849 (1997).

C. Petit, J. Legrand, V. Russier, and M. P. Pileni, J. Appl. Phys., 91, 1502 (2002).

3. V. F. Puntes, K. M. Krishnan, and A. P. Alivisatos, Science, 291, 2115 (2001)

4. V. F. Puntes, D. Zanchet, C. K. Erdonmez, and A. P. Alivisatos, J. Am. Chem. Soc., 124, 12874 (2002)

5. S. Sun and C. B. Murray, J. Appl. Phys., 85, 4325 (1999).

6. S. Ram, Mater. Sci. Eng., A, 304-306, 923 (2001).

7. N. Chakroune, G. Viau, C. Ricolleau, F. Fiévet-Vincent, and F. Fievet, J. Mater Chem., 13, 312 (2003).

8. T. Hinotsu, B. Jeyadevan, C. N. Chinnasamy, K. Shinoda, and K. Tohji, J. Appl Phys., 95, 7477 (2004).

9. S. Yagi, H. Nakanishi, E. Matsubara, S. Matsubara, T. Ichitsubo, K. Hosoya, and Y. Matsuba, J. Electrochem. Soc., 155, D474 (2008).

10. S. Yagi, H. Nakanishi, T. Ichitsubo, and E. Matsubara, J. Electrochem. Soc., 156 D321 (2009).

11. S. Yagi, T. Koyanagi, H. Nakanishi, T. Ichitsubo, and E. Matsubara, J. Electrochem. Soc., 155, D583 (2008)

12. M. D. L. Balela, S. Yagi, Z. Lockman, A. Aziz, A. Amorsolo, Jr., and E. Matsubara, J. Electrochem. Soc., 156, E139 (2009)

13. S. Yagi, T. Nakagawa, E. Matsubara, S. Matsubara, S. Ogawa, and H. Tani, Electrochem. Solid-State Lett., 11, E25 (2008).

14. M. Pourbaix, Atlas of Electrochemical Equilibria in Aqueous Solutions, p. 384 CEBELCOR, Brussels (1966).

15. C.-L. Lee, C.-M. Tseng, S.-C. Wu, and R.-B. Wu, Electrochem. Solid-State Lett., 11, D27 (2008).

16. T. Sugimoto, J. Colloid Interface Sci., 309, 106 (2007).

17. J. Chivot, L. Mendoza, C. Mansour, T. Pauporté, and M. Cassir, Corros. Sci., 50, 62 (2008). 